\title{
A SOLUTION OF RURAL INFORMATION NETWORK ACCESSING
}

\author{
Lu Yang *, Jun Xiao \\ College of Information and Electrical Engineering, China Agricultural University, Beijing, \\ China, 100083 \\ * Corresponding author, Address: P.O. Box 142, China Agricultural University, 17 Tsinghua \\ East Road, Beijing, 100083, P. R. China,Tel: +86-10-62342590,Email: yanglumail@263.net
}

Abstract: Along with the development and permeation of Internet, it has become an important commercial platform to spur economic development. Aimed at practical problems such as laggard network infrastructure, low economic supportability and inadequate literacy in country area, China has brought up rural information utilities like agricultural information machine, which can provide country families with basic agricultural information and meet their demand because of its rather cheap hardware cost and simple operation. However, the Internet resource available for agricultural information machine is limited, and it will fail to satisfy the country users as their need for Internet information keeps enhancing. This paper is to present an appropriate scheme of information network accessing to solve the deficiency of agricultural information utilities, and a pilot study on the rural information prolongation with a simulation experiment designed to validate.

Keywords: agricultural information machine, set-top box, information network

\section{INTRODUCTION}

Internet has become more and more important. For the development of agricultural in particular, the Internet can provide information promptly, and has the potential to promote China's agricultural development in an obvious way. However, some practical factors are restraining agriculture employees from obtaining abundant information on the Internet. The living condition in countryside keeps improving, though, practical difficulties such as laggard communication infrastructure, farmers' inadequate literacy, low family

Yang, L. and Xiao, J., 2008, in IFIP International Federation for Information Processing, Volume 259; Computer and Computing Technologies in Agriculture, Vol. 2; Daoliang Li; (Boston: Springer), pp. 1001-1010. 
income and economic supportability are ubiquitous in countryside. Therefore a network accessing solution suitable for nowadays rural actuality is a crying need.

\section{INTELLIGENT AGRICULTURAL INFORMATION MACHINE}

Aimed at practical problems such as laggard network infrastructure and inadequate literacy in country area, China has brought up several rural information utilities, which have already been put into use in some districts.

The Ministry of Science and Technology of the People's Republic of China has cooperated with Beijing Guangcai Agricultural Information Network Technology Co., Ltd. to develop the System of China's Agricultural Information Accessing into Countryside, which has been successively demonstrated as part of the Technology Information Accessible to Every Country Project in eleven provinces and fourteen districts. It has created good economic benefit for local farmers, helping them to head towards a better-off life (He Jiankun et al., 2003).

Heilongjiang GM Telecom Paging Co., developed GM agricultural information machine to change the situation that some rural districts in the province lack of technology information and difficulties arisen in breeding and planting cannot be solved in time.

In June 2007, 17 sets of agricultural information machine arrived at 17 administrative villages in Machangying town of Pinggu district, Beijing, opening the door of convenience for all the farmers to detailed information on agricultural information, prices of agricultural products, medical treatment and health care, whether forecast, social news and the like.

Among all the agricultural information utilities, the intelligent agricultural information machine developed by Beijing Zhongxunxiongfeng Technology Co., Ltd. of Chinese Academy of Science is relatively developed and representative. Here is the brief introduction below.

\subsection{Primary applications}

Agricultural information machine is connected to a certain server then presents information from the server on a TV set, and users operate with a remote controller to obtain information.

For the time being, agricultural information machine has several main functions as below:

1. Information downloading. Servers provide various kinds of information to rural families such as information on market, supply \& demand and the like. Users download through agricultural information machine the 
information renewed on servers everyday to the local storage so that they can take a browse at any time.

2. Information release. Users can also upload their information to servers. Released information is mainly about supply and demand. After servers' simple process, the information will be released on the servers for other users to download.

3. Communication. Service providers will give each user an account similar to an E-mail box, each corresponding to some information storage space. Users can send information to each other through accounts to communicate.

4. Surfing. The information machine makes simple WAP site accessing available.

\subsection{Strongpoint}

Agricultural information machine takes China's urban actuality into consideration, thus becomes acceptable to rural users. Its main strongpoint is:

1. Low hardware cost. Of all the system, the only thing that rural families need to buy is agricultural information machine since TV set is made use of as the vision device. Compared with PC, the cost has been lowered greatly to be affordable to rural families.

2. Convenient operation. Using remote controller as the controlling device saves a lot of time of study. With simple introduction of the manual, users can easily operate following the direction of interfaces or icons.

3. Easy maintenance. Agricultural information machine is designed with a simple structure to ensure a simple installation. All users need to do is to connect wires and setup user account, password and gateway under the direction of the manual.

\subsection{Shortcoming}

Agricultural information machine has its own shortcomings, among which the most extrusive one is the shortage of information. The current information machine only has access to appointed servers and WAP sites. Servers provide rather fixed services and only WAP sites are up to users' choice. Since WAP sites are primarily for mobile users, its information content is quite small compared with abundant information on Web sites.

The development of countryside will lead to rural families' unsatisfactory with information supplied by the information machine, and it will become a necessity to make the widest range of Web information accessible to rural families. 


\section{A RURAL INFORMATION NETWORK ACCESSING SOLUTION DESIGN}

\subsection{Problems}

In practical use, problems below become obstacles to Web site visiting.

\section{Bandwidth of rural network}

The infrastructure of Chinese rural network is relatively laggard, and the main way to visit Internet is depended on dial-up technology through low bandwidth. Normally, the size of a Web page is above $100 \mathrm{~kb}$, and the demand for bandwidth becomes larger with multimedia information like pictures and sound added.

\section{Information presentation and operation}

First of all, most Web sites are designed for computer users with the resolution of $1024 * 768$ as the displaying area, which is not possible on a TV set. If the visual effect of normal browser is directly presented on a TV set, only a small part of the page can be seen. Secondly, normal browser presents in a way suitable for mouse and keyboard to operate, but rural users mainly use remote controllers and it's hard to operate by a few buttons.

\subsection{Solution}

\section{Web information selection}

To solve the problem of low bandwidth in countryside, it's not practical to widen bandwidth. Under the condition of low bandwidth, the only solution is to work on information quantity transmitted, that is, to cut down the information quantity with the integrality of information well reserved.

Let's start with an analysis of the structure of a typical Web site. Take Sina.com.cn as an example, its Web site structure is demonstrated in Fig. 1. The home page is divided into two parts: one contains navigation of all the channels of the Web site such as finance and entertainment, the other contains important news of every channel. The entertainment channel constitutes two parts as well: classification of its blocks and important news of them. All the news in blocks can be seen with a click on the block.

News included in the upper level is in the corresponding block as well, and a great amount of redundancy of information accumulates in this way. Thus, the integrality of Web site information can be ensured by reserving news texts in blocks. 


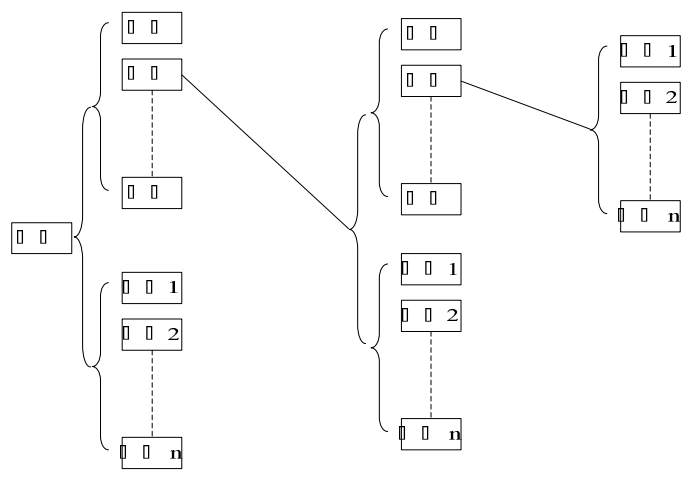

Fig. 1. The structure of web site

In the next place, a lot of multimedia information and advertisement are included in Web pages, which is unnecessary for rural users.

Therefore we can go through an appropriate selection of web information. For information on the home page of a Web site, we can just keep down navigations of its channels. As for the home page of a channel, only classifications of its blocks are going to stay. When it comes to blocks, we are going to pick up all the links to the texts. If users click to read news, only the text part of it is to be presented, eliminating other unnecessary information. Sina again, Table 1 is a comparison between before and after selection.

Table 1. Comparison result

\begin{tabular}{lcc}
\hline Page arrangement & Before selection & After selection \\
\hline Home page & $200 \mathrm{~kb} \pm$ & $<10 \mathrm{~kb}$ \\
Home page of channels & $200 \mathrm{~kb} \pm$ & $<10 \mathrm{~kb}$ \\
Blocks of channels & $100 \mathrm{~kb} \pm$ & $20 \mathrm{~kb} \pm$ \\
News text & $100 \mathrm{~kb} \pm$ & $<10 \mathrm{~kb}$ \\
\hline
\end{tabular}

After selection process, the information quantity has been cut down by large, lowering enormously the demand for network bandwidth. Meanwhile, the integrality of information on Web sites is preserved to satisfy rural users.

\section{A design of suitable presenting mode}

The presenting mode of a common browser is not suitable for a TV set, neither for operating with a remote controller. So it's important to design a suitable presenting mode that applies to TV's low resolution and easy to operate with a remote controller.

User's operation is an interaction between people and machine, and a good interaction is the key of the product's success. In accordance with principles of user-oriented and consistency (Huo Youren et al., 2006), the design of presenting mode is as Fig. 2 shows, which is easy to learn and cognize and can be accepted and mastered very soon by users. 


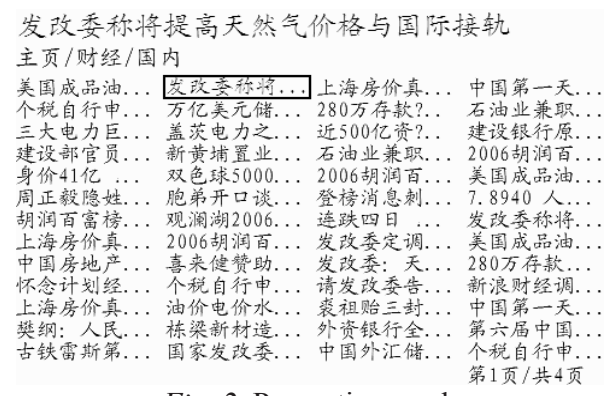

Fig. 2. Presenting mode

The first line of the presented interface corresponds to the part below framed in black, representing the link user choose. It is in larger font to emphasize the importance and make operation easier. The second line is used to indicate where users are, avoiding users getting lost in the Web. The following part is most important in the interface, which concludes the information of the Web site that users need. To enhance the efficiency of user's operation, links are arranged in matrix, and in this way the content of one page is enlarged. The last line represents the quantity of information in the page to show to users.

By this means, users can browse and choose information through a simple click on the buttons of the remote controller. On the whole, the presenting mode is simple, clear, focused and pleasant to use, providing a good solution to the problems caused by the difference of presenting device and operating tools.

\subsection{Scheme design}

Combined with the strongpoint of agricultural information machine, the design provides a solution of network accessing; actualizing country family visiting Web sites, and the structure of it is showed in Fig. 3. The system constitutes four parts: user, TV set, STB (set-top box) and information server.

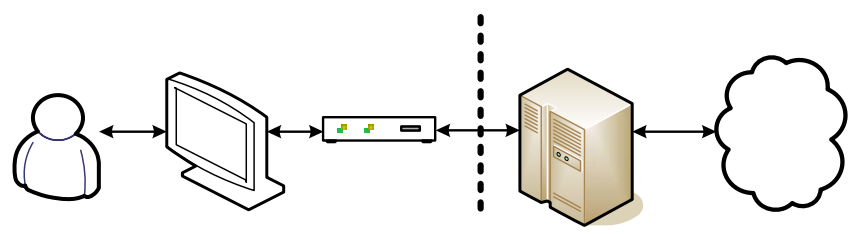

Fig. 3. The structure of system solution 


\subsubsection{Functions of STB}

In a country family there is a STB (Lu Feng, 2006) which is connected to the Internet through low bandwidth Dial-up. Users get a link to information server by designating the gateway address to STB. The interaction between users and information servers is in the charge of STB.

First of all, STB receives instructions from users. If it is asking information server to visit Web site, STB will transmit the request to the information server. If it is asking STB to process cached information, STB will follow the instruction and submit corresponding cached information, for example, the choice of links.

In the next place, STB is responsible for presenting information to users. It shows the information returned from the information server on a TV in the presenting mode designed in section 3.2 for users to browse.

\subsubsection{Functions of information server}

Information server manages STB in its range. As the processing ability of servers varied, a server could be used for one county, or for one town. Information servers can be connected to Internet by fiber or other means to have a wide Bandwidth.

In the architecture of the Internet, an information server plays the role of an explorer, obtaining information from Web servers through HTTP protocol. Meanwhile, it acts as a server when communicating with STB, through HTTP protocol as well.

Firstly, an information server functionates as an explorer to visit Web sites. It receives the request of visiting from STB in its range, then transits the request to HTTP request to send to relevant Web sites, and at last obtains the information returned from Web sites.

Secondly, an information server has a strong ability of information processing. For information already in local-storage, it can reply the request of STB directly. At the same time, it manages the redundancy of information, and sets up a sententious information image for users. In process of information server's design and implementation, we need focus on resolutions of problems like information classification and management, redundancy elimination, maintenance of information validity and information search. Solutions of those problems will be described in other papers. 


\section{ILLUSTRATION OF EXPERIMENT RESULT}

\subsection{Simulation scheme}

Based on the above scheme, we have designed a simulative experiment, the structure of it showed in the Fig. 4. The structure contains two computers, computer 1 simulates information server; computer 2 simulates STB and TV, with monitor screen representing the screen of TV and buttons on keyboard representing those on remote controller.

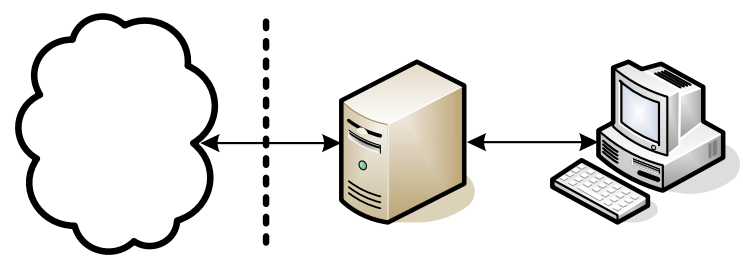

Fig. 4. The structure of simulative experiment

In the simulation, computer 2 connects with computer 1 , sending the visiting request to computer 1 , and then presents the information returned from computer 1 in the designed mode demonstrated in section 3.2.

Computer 1 connects to the Internet, and after receiving the request from computer 2, it transmits it to HTTP request to send to corresponding Web sites. Having obtained information from a Web site, computer 1 processes the information in the way designed in section 3.2, and sends the processed information back to computer 2 as the final step.

The overall simulation contains the important parts of the solution and has implemented the key functions, thus we can say it is conform to the requirement of an actual simulation.

\subsection{Illustration of result}

The result of experiment has achieved the purpose of design, the demonstration of result showed below. Let's visit www.163.com for illustration.

User sends the request to server, which gets the information on homepage, after selection, what shows up is like in Fig. 5, user selects sports channel from the news channel of the Web site. 


\begin{tabular}{|c|c|c|c|}
\hline VIP邮籍 & & & \\
\hline & 明星 & 财经 & $\begin{array}{l}\text { NBA } \\
\text { 科技 }\end{array}$ \\
\hline 汽车 & 手机 & 女人 & 游戏 \\
\hline 军事 & 探索 & 图片 & 博客 \\
\hline 奥运 & 英超 & 电影 & 商业 \\
\hline 证券 & 基金 & 车型 & 数码 \\
\hline 时尚 & 情爱 & 招䏇 & 厉史 \\
\hline 播吧 & 杂志 & 论坛 & NULL \\
\hline NULLL & NULL & NULL & NULL \\
\hline NüLL & NULL & NULL & NULL \\
\hline NULL & NULL & NULL & NULL \\
\hline NULL & NULL & NULL & NULL \\
\hline NULL & NULL & NULL & 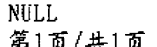 \\
\hline
\end{tabular}

Fig. 5. Experiment illustration 1

User clicks to enter the chosen channel, what presents itself after selection of the server is showed in Fig. 6 classifications of blocks in the sports channel.

\begin{tabular}{|c|c|c|c|}
\hline \multicolumn{4}{|c|}{$\begin{array}{l}\mathrm{CBA} \\
\text { 主页/体育 }\end{array}$} \\
\hline 滚动 & 评论 & 专题 & 08奥运 \\
\hline 相舟 & 旅游 & 拍卖 & 姚明 \\
\hline CBA & 男篮 & 国际 & 意甲 \\
\hline 海外 & 彩蔡 & 西甲 & 德甲 \\
\hline 欧冠 & 比分 & 国内 & 中超 \\
\hline 国足 & 中甲 & 女足 & 综合 \\
\hline 网球 & F1 & 刘翔 & 乒羽 \\
\hline NULL & NULL & NULL & NULL \\
\hline NULL & NULL & NULL & NULL \\
\hline NULL & NULL & NULL & NULL \\
\hline NULL & NULL & NULLL & NULL \\
\hline NULL & NULL & NULL & NULL \\
\hline NULL & NULL & NULL & NULL \\
\hline
\end{tabular}

Fig. 6. Experiment illustration 2

User chooses a block, and then clicks to enter. All the news links that user wants are presented as Fig. 7 shows.

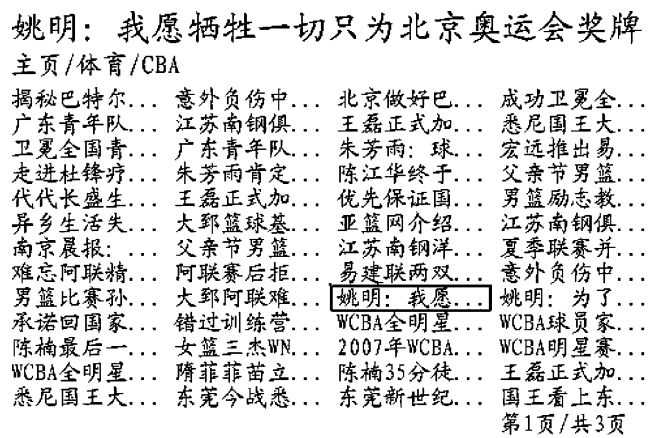

Fig. 7. Experiment illustration 3 
Fig. 8 shows what happens after user clicks to read a chosen piece of news.

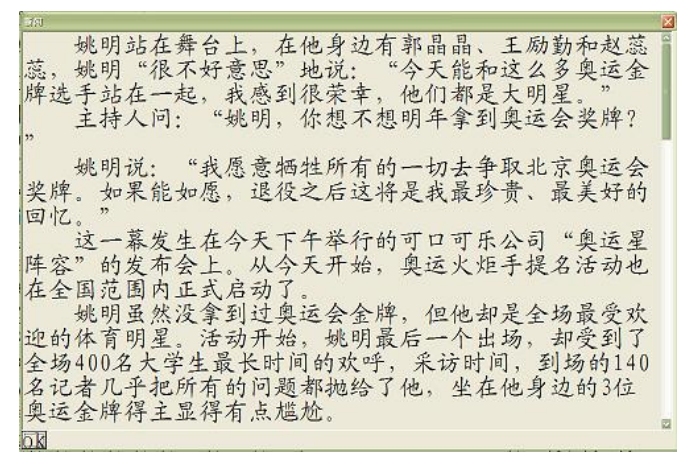

Fig. 8. Experiment illustration 4

User finishes with text reading thanks to buttons of up roll and down roll. By far, a successful browse of web information has been completed.

\section{CONCLUSION}

A key issue of rural economic development is how to advance informatization in countryside, which has a serious problem that information provided by agricultural information machine is too limited to meet the demand of country's families. In order to extend county's information network and solve the shortage of information provided by agricultural information machine, this paper analyses the status quo in countryside and designs an applicable solution for information network accessing validated by experiments. We hope that it will become a reference for agricultural informatization. The design and implementation of information server is very important for this solution, and we will discuss key techniques in later paper.

\section{REFERENCES}

He Jiankun, Ji Gang 2003, Record of Technology Information Comes to Villages Project Helping towards Better-off. http://www.stdaily.com/gb/misc/2003-11/14/content_171007.htm.

Huo Youren, Xie Zhibin 2006, Exploring Designing Method for Human-machine Interface of Information Products. Journal of Ningbo University (science and technology edition), 1:107-109 (in Chinese).

Lu Feng 2006, Functions and Development of IP Set-top Box. Computer Knowledge and Technology, 9:21-24 (in Chinese). 